\title{
Flor y la magia de la niñez
}

Recibido: 01.07.2017 / Aprobado: 04.07.2017

Por Bygocha d' Amalia ${ }^{1}$

El Instituto Martin Luther King, en la víspera de la celebración de sus 25 años de fundación (19932018), desea inaugurar en la revista Cultura de Paz, una nueva etapa de promover y reconocer las artes plásticas infantil, la que inauguramos con Flor Amalia (8 años), hija de nuestro querido amigo y fiel colaborador de nuestra revista, Bygocha d' Amalia. Les invitamos a todos a aprovechar este espacio como una forma de promover también el talento artístico infantil.

"Gracias por publicar mi pintura, pienso que es bonito que muchos niños la vean, pintar es siempre un juego y me divierto. Todo niño puede hacerlo, porque tiene fantasias. Me gusta pintar ahora bosques, animales y mis fantasías". Flor Amalia Beucker Andreae (9 de mayo del 2009, Utrecht, Holanda) holandesa-nicaragüense.

Genial la idea de brindarle un espacio a la obra de Flor en la portada de Cultura de Paz. Esta obra la pintó especialmente para regalársela a mi madre que cumplió 75 años el 10 de julio. Mi madre aún no sabe sobre su publicación, la que fue directo a la colección privada de ella en Nicaragua.

Flor se sentirá sorprendida al saber esta noticia, sobre todo, que a través de ella se se está haciendo un llamado a promover el arte infantil en mi país jes una excelente idea! En ese sentido podré aportar con ideas o clases, si es posible virtuales, para que ustedes, como Instituto Martin Luther King, promuevan más el arte con los niños.

Flor empieza a dar sus primeros pasos en el mundo del juego del color, sentada en mis piernas, cuando estaba pintando, le encantaba estar sentada mientras pintaba, tenía como 6 meses y observaba lo que estaba pintando y queria tener el pincel en sus manitas, yo pintaba una flor en formato grande y decidí darle el pincel, lo tomó, puso el pincel en el lienzo con mucha seguridad de hacer su primer trazo, claro, luego debí limpiar el lienzo, porque mi flor que estaba casi

terminada, le había pintado una línea, mi otra Flor. Luego buscó el agua y metió el pincel y quería, luego limpiarlo en un trapo, era lo que todos los días que la cargaba me miraba hacer.

Soy del criterio que si una hija mía me pide el pincel, se lo doy, creo que los niños saben lo que desean hacer, en mi obra de arte la primer persona que dejé sin temor que pintara sobre mi obra fue a mi hija mayor, luego a Flor. En este caso, claro para ella era un juego y sigue siendo un placer y un juego el pintar, no la obligo. Le digo siempre, acá están los lienzos, los colores, lo que desees y pinta cuando quieras. Lo importante en esta etapa, es jugar con sus juguetes, sus amiguitas y amiguitos, eso es vital para su formación, jugar y jugar, aun con el color, si te olvidas jugar y socializar con los demás, luego no podrás crear.

De hecho algunas veces, es mi asistente en las clases que doy de arte en las escuelas primarias.

Ella hizo su primer trazo sobre mi obra y luego empezó a pintar su mundo fantástico, como los tres cerditos y el lobo, un cuento que le leía todas las noches y ella pintaba o manchaba con el pincel o sus manitas,

1 Artista plástico nicaragüense, padre de Flor Amalia. 
algo abstracto haciendo círculos con sus manos o pincel y decía que era los tres cerditos y el lobo y asi, cada historia que le leía, trataba de plasmarlos en sus primeras obras.

$\mathrm{Re} \mathrm{g} \mathrm{u} \mathrm{la} \mathrm{r} \mathrm{m} \mathrm{e} \mathrm{nte}$ visitamos el jardín botánico y el mariposario y de ahí hizo una obra haciendo círculos con sus manitas y me dijo, papá ese el el jardín de las mariposas y efectivamente, cuando lo ves parecen mariposas, mi aporte diría, es hacerles ver a ellas, tanto a Flor de 8 y Roos de 3 y medio, que deben jugar, no olvidar jamas sus fantasías, que el pintar es un placer, un juego y que si les aburre, dejen de pintar y a jugar. Luego vendrán las ganas de pintar. El arte es eso, un juego, una diversion y si te deja de divertir, no pintes.

Flor ha venido pintando, siempre sobre la línea de la fantasía y figuración. A veces pinta bodegones, autoretratos, retratos, a otros ninos o a mí, paisajes como el último que está en facebook. Ese lo empezó en la escuela, en la cual doy clases, ella me acompaña y pinta y lo hizo en 4 sesiones de 1 hora. Reciben una foto y a interpretarla lo mejor que puedan, sin llegar a ser como la cámara, en este caso no le explico a ella, porque debo explicar a los otros niños, ella lo entiende, pero confío que ella lo puede hacer sin mi ayuda en ese momento. Luego mi ayuda es teórica y sobre la pizarra, le explico cómo usar los pinceles para que den diferentes efectos, las veladuras, la proporción, cómo pintar el fondo, luego dibujar el tema, que lo hace directamente con el pincel con color, no usar el grafito. La experiencia con niños me ha enseñado que el grafito para ellos es aburrido, ellos quieren pintar, mancharse, ver el color.

Flor tiene unas 60 obras pintadas y unas 6 esculturas en barro, algunas de ellas se las ha regalado a sus abuelitos, tíos, entre otros. Otras están en casa, su temática empieza en la fantasía, con la libertad de crear sus propios mundos, entrando también al realismo, pero con la magia de la niñez, ella tiene un trazo seguro, sabe cuándo debe hacer un trazo y una curva. Sabe que puede equivocarse muchas veces, pero ahí está la receta para

\section{Julio 2017 \\ Utrecht, Holanda}

